\title{
Severe myalgia in familial Mediterranean fever: clinical and ultrastructural aspects
}

\author{
D SCHAPIRA, ${ }^{1}$ R LUDATSCHER ${ }^{2}$ M NAHIR, ${ }^{1}$ M LORBER, \\ AND Y SCHARF
}

From the Departments of ${ }^{1}$ Rheumatology and ${ }^{2}$ Pathology, Rambam Medical Center, and Faculty Medicine, Technion-Israel Institute of Technology, Haifa, Israel

SUMMARY Severe myalgia is an uncommon feature of familial Mediterranean fever (FMF). $\mathrm{A}_{\stackrel{c}{c}}^{\mathrm{c}}$

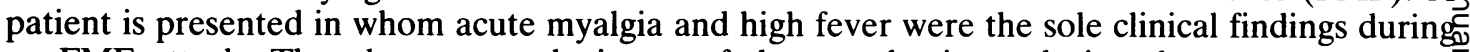
an FMF attack. The ultrastructural picture of the muscle tissue during the acute stage wask characterised by a large deposition of collagen fibrils. The myalgia subsided during colchicine $\overrightarrow{0}$ treatment. The clinical and ultrastructural features of myalgia in FMF are discussed in the light op the relevant literature.

Key words: periodic fever, muscle pain, collagen fibrils.

Familial Mediterranean fever is a disease characterised by paroxysmal and self limiting attacks of fever, peritonitis, synovitis, and pleuritis. Sephardic Jews, Armenians, Turks, and Arabs are predominantly affected through a recessive autosomal mode of transmission. In most patients the symptoms start before the age of 20 years. ${ }^{1}$ Colchicine has been accepted as an effective therapeutic agent in the treatment of $\mathrm{FMF}^{2}$ and in the prevention of its ominous prognostic feature, amyloidosis. ${ }^{3}$

We present a patient in whom severe myalgia and fever were the sole clinical findings during an FMF attack.

\section{Case report}

A 22 year old woman of Iraqi descent was admitted because of severe calf pains. From the age of 6 years multiple episodes of self limiting arthritis of the ankle and knee joints had been recorded. She had not been investigated previously. Five days before admission excruciating pain of both calves and high fever appeared. The pain was so severe that

Accepted for publication 17 July 1987.

Correspondence to Dr D Schapira, Department of Rheumatology, Rambam Medical Center, Haifa 35254, Israel. standing or walking were impossible and a wheelchair was used. On examination the patient was febrile $\left(39^{\circ} \mathrm{C}\right)$. Both calves were slightly swollen warm, and very sensitive; the slightest touch elicited severe pain. The rest of the physical examinationsand the joint examination were not contributory 3 . The Westergren erythrocyte sedimentation rate was $80 \mathrm{~mm} / 1 \mathrm{st} \mathrm{h}$, the $\mathrm{C}$ reactive protein +++ , the white blood cell count $12 \cdot 8 \times 10^{9} / 1$ with normal differential.o Blood urea nitrogen, glucose, creatinine, bilirubin, alkaline phosphate, transaminase, calcium, phos phorus, uric acid, total protein and albumin, serum complement, protein electrophoresis, and im-O munoelectrophoresis were normal. Serum laction dehydrogenase, creatinine, phosphokinase, and N aldolase were normal, and no myoglobin was foundo in the urine. Serological tests for various infectious diseases, rheumatoid and antinuclear factors, antismooth muscle, antimitochondrial and antiparietaks cell antibodies were negative. Blood and urinaryo cultures were sterile. Serum fibrinogen was $6 \cdot 2 \mathrm{~g} / \overline{6}$ (normal 2.0-4.0). Roentgenograms of the chest, the lower extremity joints, and the tibial shafts wereक्ष normal, as was an electromyographic study of the affected areas. A skin and muscle biopsy of the right calf was performed. 


\section{Materials and methods}

The tissues for histology were fixed in formalin, embedded in paraffin, and stained with haematoxylin-eosin; phosphotungstic acid-haematoxylin; Congo red. For electron microscopy small pieces of muscle were immediately fixed with ice cold $3 \%$ glutaraldehyde in cacodylate buffer, $\mathrm{pH} 7 \cdot 3$, for one hour, postfixed with $2 \%$ osmium tetroxide, dehydrated in alcohol, and embedded in Epon. Sections $1 \mu \mathrm{m}$ thick were stained with toluidine blue and examined under a light microscope for orientation of muscle fibres. Thin sections were stained with uranyl acetate and lead citrate and examined under a Zeiss 9S electron microscope.

\section{Results}

A histological examination of the striated muscle and of the skin did not show signs of vasculitis. There was an increase of the collagen tissue in the interstitium of the muscle and also a few inflammatory cells.

The electron microscopic examination showed that most muscle fibres were of normal size, but atrophic muscle cells with a diameter of 17-20 $\mu \mathrm{m}$ were dispersed among the regular sized cells. The sarcomere pattern was well preserved. Irregularities of the $\mathrm{Z}$ band were frequently seen in atrophic and normal sized muscle cells. The sarcolemma was moderately widened.

The most striking changes occurred in the endomysial and perimysial spaces between muscle fibres. These spaces were occupied by increased amounts of collagen fibrils which often closely applied upon the sarcolemma (Fig. 1). Masses of collagen fibrils occurred also around the wall of the small venules and sometimes appeared between the endothelial layer and the smooth muscle layer of the venular wall (Fig. 2). The perivascular basement membrane of capillaries and of small venules was uniformly and moderately widened (Fig. 2). Small infiltrates composed of fibroblasts, macrophages, and a few mast cells were seen in the interstitial space.

Rectal biopsy was denied by the patient. Treatment with diclofenac sodium $150 \mathrm{mg} /$ day and later with corticosteroids (prednisone $30 \mathrm{mg} /$ day) failed to bring about any improvement. The severe myalgia and the functional disability continued. On the fifth day of hospitalisation arthritis of the right knee appeared. The joint was aspirated and $70 \mathrm{ml}$ of a cell rich fluid $(80000 \mathrm{cells} / \mathrm{ml})$ was evacuated. The fluid was sterile and no crystals were found. The diagnosis of FMF presenting at this stage as severe myalgia was supported by the past history of periodic and self limiting arthritis, by the patient's ethnic origin (non-Ashkenazi Jew), and by an

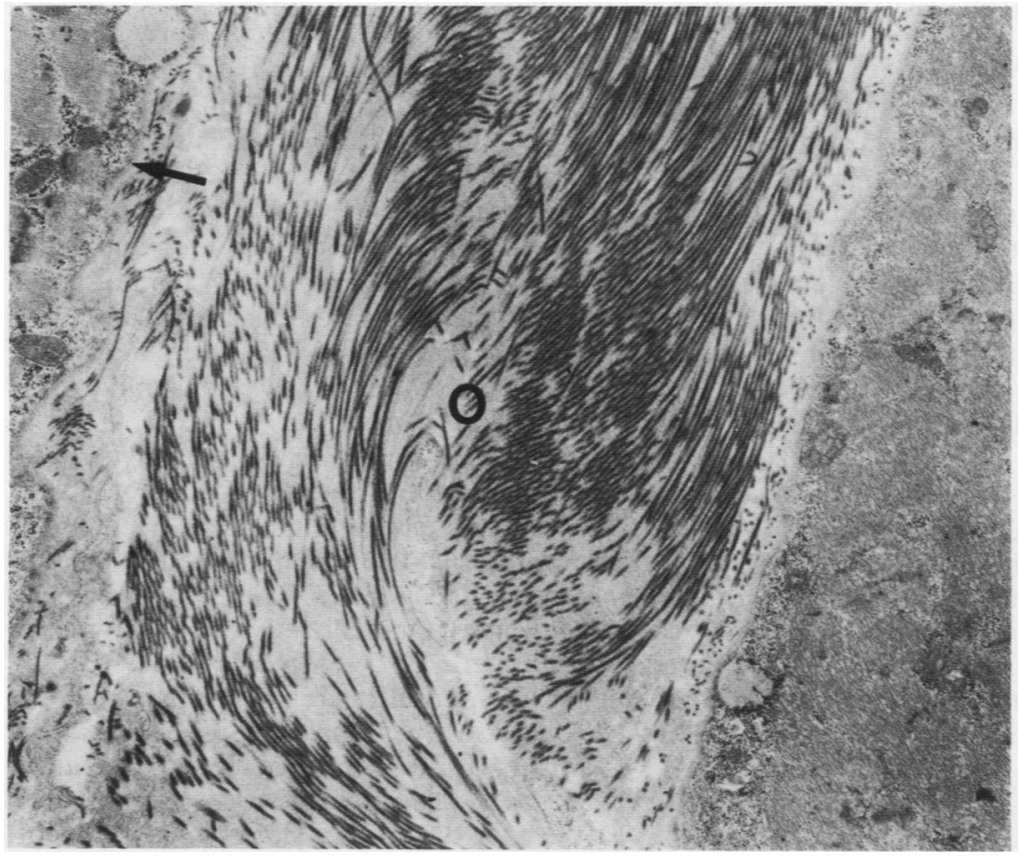

Fig 1 The electron micrograph shows a large amount of longitudinally sectioned collagen fibrils $(O)$ which occupy the endomysial space. Portions of the striated muscle fibres appear at both sides of the endomysial space. In some areas the collagen fibrils apply upon the sarcolemma (arrow). 


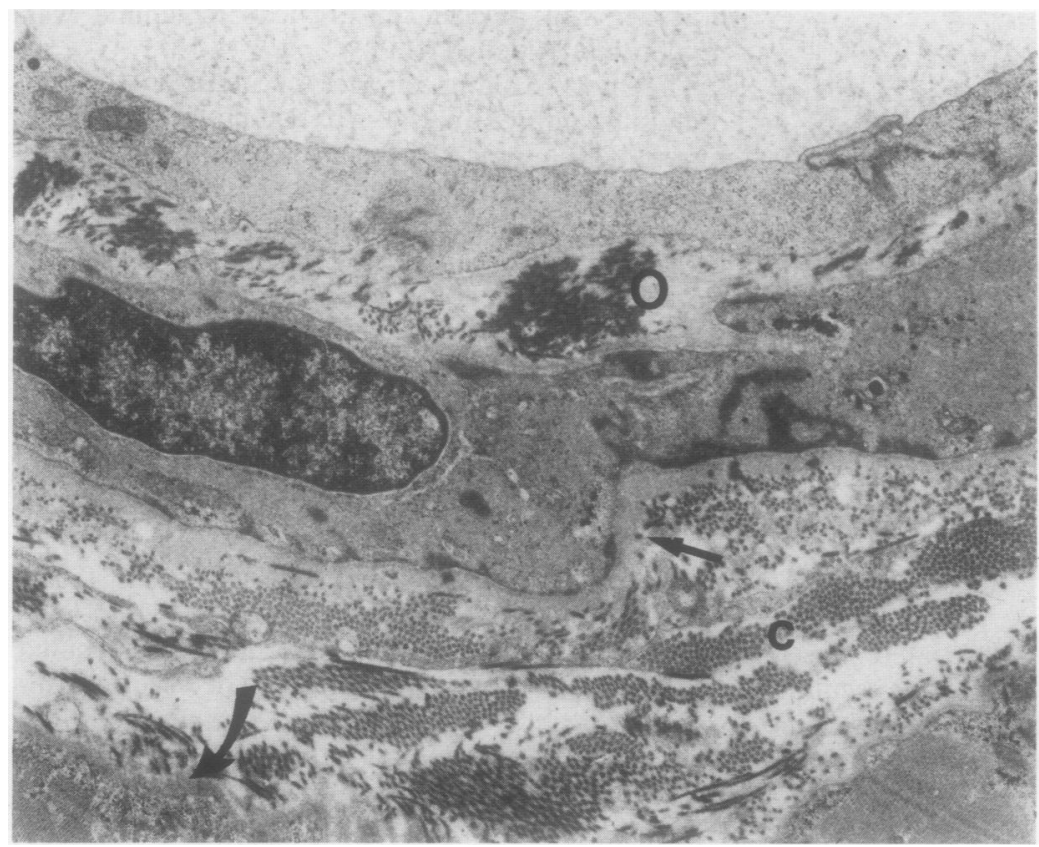

Fig. 2 Part of the wall of the

appropriate family history (a younger sister suffering from recurrent peritonitis and arthritis). Treatment with colchicine $1.5 \mathrm{mg} /$ day was instituted. Three weeks after the beginning of the attack the myalgia subsided. During the follow up no further episodes of arthritis or muscle pain occurred.

\section{Discussion}

The classical clinical manifestations of FMF are well known and have been described in large series of patients. ${ }^{45}$ The less common erysipelas-like skin eruptions and non-specific symptoms such as prolonged lymphadenopathy, periodic meningitis, jaundice, cutaneous vasculitis, recurrent pericarditis, severe ovarian and testicular pain and tenderness, pancreatitis, and periodic parotid swelling have also been reported to be associated with the febrile paroxysms. ${ }^{1}$

Muscle pain may accompany the other clinical features of FMF. Its presence is usually shadowed by the other impressive manifestations of the disease. Nevertheless, using directed questions it has been detected in up to $20 \%$ of the patients. ${ }^{6}$ As in some cases of FMF arthritis, the muscle pain seems to be potentiated by effort and appears usually in the evenings after prolonged standing and walking. The pain subsides in a few hours but sometimes it lasts for a few days. Pain, tenderness, and spasticity have been described in the muscle area close to the inflamed joints. ${ }^{7}$ The histological picture is that of increased vascularity, atrophy, and fibrosis. $^{8}$

Severe myalgia as the sole feature of the disease $\overrightarrow{\vec{P}}$ or as one of its main clinical manifestations is rare. It $\stackrel{3}{3}$ has been described in a few studies. ${ }^{579-15}$ In one patient periodic fever and myalgia were the soleo manifestations of the disease ${ }^{15}$ As in our case the diagnosis was supported by the ethnic origin of the patient, by the family history, by the wellbeing윽 between the attacks, and by the excellent response to colchicine therapy. Other authors describe the spectacular response of severe periodic shoulder and hip girdle myalgia to intravenously administered 은 colchicine. ${ }^{13}$ All the authors emphasise the intensity of the attacks, which last two to three weeks. In some patients muscle atrophy was observed after ơ protracted attacks. $^{7}$

Severe myalgia without arthritis is relatively rare ${ }_{0}^{\circ}$ in FMF, occurring in two to four of 100 patients. ${ }^{16} \mathrm{\omega}$ Therefore it is understandable that most histological and ultrastructural studies have been done on the synovia and its related tissues, whereas the changes $\Phi$ of the skeletal muscle have been very little investi- + gated.

Biochemical and ultrastructural changes are $\frac{\overrightarrow{0}}{\overrightarrow{0}}$ known to occur in the interstitial tissue matrix in $\stackrel{?}{\oplus}$ FMF, classically described under the form of amy- $\stackrel{\perp}{\varrho}$ loid AA deposits. The present case is interesting owing to the fact that no amyloid fibrils could be $\delta$ 
detected in our material; deposition of collagen fibrils, however, appeared in increased amounts in the perivascular spaces and in the endomysial and perimysial spaces of the striated muscle. To our knowledge these alterations have not been previously recorded at the ultrastructural level.

\section{References}

1 Eliakim M, Levy M. Ehrenfeld M. Recurrent polyserositis. Amsterdam-New York-Oxford: Elsevier/North-Holland Biomedical Press, 1981: 15.

2 Levy M, Eliakim M. Long-term colchicine prophylaxis in familial Mediterranean fever. Br Med J 1977; ii: 808.

3 Zemer D. Colchicine in the prevention and treatment of amyloidosis in familial Mediterranean fever. $N$ Engl $J$ Med 1986; 314: 1001-5.

4 Sohar E, Gafin J, Pras M. Heller H. Familial Mediterranean fever. A survey of $\mathbf{4 7 0}$ cases and review of the literature. Am J Med 1967; 43: 227-52.

5 Schwabe A D, Peters R S. Familial Mediterranean fever in Armenians. Analysis of 100 cases. Medicine (Baltimore) 1974; 53: 453-62.

6 Zemer D. Muscle pains in familial Mediterranean fever. Harefuah 1984; 106: 232-3.

7 Heller H, Gafni J, Michaeli D, et al. The arthritis of familial Mediterranean fever. Arthritis Rheum 1966; 9: 1-17.

8 Stein H, Yarom R, Makin M. Synovitis of familial Mediter- ranean fever. A histologic and ultrastructural study. Virchows Archiv. A. Pathological Anatomy and Histology 1975; 367: 263-72.

9 Siguier F, Zara M. Func-Brentano J L. Lagrue G. Réflexions sur la maladie dite périodique. Semin Hop (Paris) 1953; 29: 3649-58.

10 Benhamou E, Albou A, Destaing F, Ferrand B, Boineau N. Périartérite noueuse et maladie périodique. Bull Mem Soc Med Hop Paris 1954; 70: 247-54.

11 Eliakim M, Rachmilewitz M, Rosenmann E, Niv A. Renal manifestations in recurrent polyserositis (familial Mediterranean fever). Isr J Med Sci 1970; 6: 228-45.

12 Bitar E, Naffah J, Nasr W, Khoury K. La maladie périodique (polysérosite paroxystique familiale). Rev Rhum Mal Osteoartic 1976; 43: 267-72.

13 Delcambre B, Defrance D, Duquesnoy B, Deremaux d'Eshougues R. Manifestations musculaires sevères au cours d'une maladie périodique avec spondylarthrite ankylosante. Action de la colchicine. Rev Rhum Mal Osteoartic 1979; 46: 487-90.

14 Nathanson M, Scott G, Perelman R. Manifestations musculaires de la maladie périodique. Deux observations chez l'enfant. Ann Med Interne (Paris) 1981; 132: 487-9.

15 Kuhnreich E, Naschitz J E, Kohn A, Yeshurun D. Familial Mediterranean fever presenting with recurrent severe myalgia. Harefuah 1984; 106: 209-10.

16 Schlesinger M, Kopolovic J, Viskoper R J, Ron H. A case of familial Mediterranean fever with cutaneous vasculitis and immune complex nephritis: light, electron and immunofluorescent study of renal biopsy. Am J Clin Pathol 1983; 80: 511-4. 